\title{
The Role of Online Education on the Perception of the Students during Coronavirus Lockdown
}

\author{
Canan Kala ${ }^{1}$ \\ ${ }^{1}$ Department of English Language and Literature, Faculty of Education and Humanities, International \\ Burch University, Sarajevo, Bosnia and Herzegovina \\ Correspondence: Canan Kala, International Burch University, Sarajevo, Bosnia and Herzegovina. \\ Email: canan.kala@stu.ibu.edu.ba
}

Doi: 10.23918/ijsses.v8i1p212

\begin{abstract}
The coronavirus process has adversely affected all sectors as well as the education sector. After revealing the negative effects of this process on students and education, this study investigated how it affected university students through a survey. The results obtained are like other results in the literature. Students who could not adapt to online education at first showed their concerns about this issue in our survey. It has been observed that online education has negative effects on students' grades as well. In addition, students often showed in the survey the idea that learning something is more important than the grades they will receive.
\end{abstract}

Keywords: Coronavirus, COVID-19, Online Education, Student Satisfaction

\section{Introduction}

The sudden emergence of the coronavirus process has forced all governments on earth to take urgent measures. The most important of these measures has emerged as lockdown of everyone at home, because this is the best method to prevent the spread of the virus. However, afterwards, all sectors in the world were adversely affected by this process and the education sector was not any exception to them. As a solution to this, an online education model was mostly developed, but initial experiences were not as expected. The process of getting used to this situation by students and teachers has forced them and as a result, some positive and negative opinions have emerged against online education.

\section{Related Literature}

\subsection{COVID 19 and Students}

COVID-19 was declared to be a pandemic on 11th March by The World Health Organization. This pandemic had previously been declared as a global public health emergency of international concern on 30th January 2020 (Adnan, \& Anwar, 2020). The virus was firstly detected in Wuhan city of China in December 2019 and spread rapidly all over the world. The first case of the infection was diagnosed as critically ill in Italy on 20th of February 2020. Then it spread very quickly in the country and all over the world causing many deaths (Riccardo et al., 2020).

Received: January 12, 2021

Accepted: March 1, 2021

Kala, C. (2021). The Role of Online Education on the Perception of the Students during Coronavirus Lockdown. International Journal of Social Sciences \& Educational Studies, 8(1), 212-225. 
The pandemic of the virus has deeply affected the whole world from the economic situation to social relations. Since the best way to protect from this new type of virus is containment measures, everybody was forced to lockdown in many countries (Mishra et al., 2020). On 6th of April 2020, UNESCO reported that more than 1,5 billion students were affected by the pandemic because they could not attend their schools at all levels of education. This number comprises of $91 \%$ of the whole student population in the world. In fact, it was implemented in 188 countries worldwide (Toquero, 2020).

The students of these ages have never been in the risk groups of the coronavirus, or very little, but they were more dangerous than adults because they carry the virus but do not indicate any symptoms of illness. For that reason, it is never possible to detect any children infected by coronavirus. The most dangerous point is that they cause the virus to spread much more quickly. One of the first precautions in all over the world was to close the schools to protect the elderly. If these severe precautions and many more had not been taken seriously, the course of pandemic would have developed even with more deadly results. Since it was a new type of virus, there was no vaccine for it and the best solution to be urgently found was social isolation of people, namely lockdown. It is because of the reason that the contamination of related illness is through contact with an infected person (Basilaia \& Kvavadze, 2020).

This pandemic came up with such effects that no generation in the world has experienced such a problem. It naturally affected many sectors deeply and education was not any exception to it. Even more, it is possible to state that education is one of the most deeply affected sectors. It affected teachers and students from many different dimensions like socially, mentally, and academically. The imminent threats of this pandemic are so challenging that the world economy is under high risk of recession together with a cause for anxiety and stress for many students. The butterfly effect is not only direct but also there are many indirect results, such that many people have lost their relatives and many others their jobs. Even more, the lockdown at home causes another tension among family members, and the students cannot concentrate on their work well (Khalili, 2020).

\subsection{Effects of Coronavirus Process on Education}

Since the best measure to be taken against the corona virus is keeping social distance, preventive practices have negatively affected the whole life as well as education. After the first temporary closure of educational institutions by the governments, this period was extended continuously and continued without education for a long time. It is necessary to consider the negative effects of the coronavirus process on education separately in the long and short term. First, while almost all the students were deprived of education at school in the short term, some of them continued their education in some way because they had the opportunity to receive online education. On the other hand, most students lacked such opportunities as they were not able to receive. These students, whose economic situation is too low to receive online education, will suffer more from the inequality of opportunity from now on. Many children who lack even the most basic communication tool used by the modern world, such as the Internet, will have greater problems due to inequality of opportunity. Primary school students, which will be particularly affected by this process, are deprived of basic knowledge such as learning to read and write and basic mathematics operations that are very necessary for them and constitute the infrastructure of future classes. Considering the critical position of the first 3 grades of primary school at the learning point, problems for these children can be expected in the coming years. This also has consequences that are expected to occur in the long 
term. Above all, it will be very difficult for children who have been deprived of education for a long time to continue with the same curriculum from where they left off when they start school later. Therefore, a decrease in the quality of education is expected (Jena, 2020). One of the most basic duties of the school is to ensure that children socialize and bring the culture of that society to children. At this point, education that is not in the school will not be able to achieve these goals regardless of how it continues. Therefore, it is impossible for the school to fulfill this duty until the day of normal education.

On the other hand, it is possible to talk about other benefits of education at school on children. Especially the fact that children in primary school age are too energetic and having a school environment where they can exert this energy is a great opportunity for them, in this case they are deprived of these gains. Moreover, children staying at home are a big problem for both themselves and their families (Fontanesi et al., 2020).

Even if the distance education model has been developed against the closure of schools in many places, it will not be possible to say that it directly corresponds to normal education. First, the time spent on education has dropped considerably. In online education, it is almost impossible for students to take as many courses as they take at school. In addition, it is not possible to maintain the same motivation in front of the computer. Children often have significant motivation problems. In addition, after children had to stay at home, the transition to online education has emerged as an extra financial burden for families. For example, a computer was required for all students in this situation. The issue of how suitable the home environment is to learn is a problem that needs to be addressed separately. First of all, it is a big problem that school discipline cannot be provided at home. Later, the fact that the parents are not at home during the day makes the indiscipline even more problematic (Di Pietro et al., 2020).

\subsection{Online Education during COVID-19 Era}

In a normal situation, the effect of such a pandemic on education is a complete cessation of education, but different results have emerged in this process. The fact that the internet is widespread all over the world and the technological devices required for education are accessible has relatively become an opportunity for education. In this case, online education can be realized in the best way possible with the best adaptation of teachers to this situation. Therefore, teachers have sought what they can give and how they can give in online education. However, it has been very difficult for them to start online education suddenly and people had no alternative in this regard. Because the teachers were not prepared for such a situation and they were obliged to start new searches when they suddenly came across them, they had much difficulty at the beginning. In fact, students who were not prepared for this situation were another challenge for teachers (Khalili, 2020, p.688).

The most appropriate form of learning takes place in social contexts, and in this case, it occurs in the form of mutual interaction and experience sharing with others. Especially in order for a high-level learning to take place, communication between students is necessary. In mutual interaction, people not only improve their cognitive skills but also their affective skills. For example, people can learn many affective characteristics such as mutual understanding, empathy with others and respect for the opinions of others through mutual communication. How much of these will be accomplished by learning online is a big question mark (Newman \& Holzman, 2013). 
According to the results of a study, students were satisfied with some aspects of online education. For example, it has had very positive results in terms of saving time for students. In addition, they stated that they did not experience the stress of getting up early in the morning and catching up to class. In addition, it was positive for them to have the opportunity to listen to the repetition of the lesson. However, they also expressed their negative opinions because of taking away socialization opportunities, staying away from people they were used to before, not being able to participate actively in lessons and not having classroom interaction (Genç \& Gümrükçüoğlu, 2020).

\subsection{Student Satisfaction}

The issue of customer satisfaction, which is one of the important research topics in economics, emerges by comparing the perceived effect of the product purchased by the customer with the expected value of that product. Many models related to this have been produced and the issue has been tried to be understood through these models. Likewise, within the framework of the new situation, how satisfied students are with the online education they received has been the subject of many studies (Chen et al., 2020).

Studies have shown that while students express their satisfaction with online education in some subjects, they also express their dissatisfaction with others. As stated above, saving time and being able to access the lecture videos later can be considered a gratifying situation. However, there are other points that cause students' dissatisfaction. For example, if the videos on the internet are more than 25 minutes, the students' desire to watch the video falls dramatically. The students stated that they could not ask questions as they wanted and missed points they did not understand. They stated that face-to-face learning is much more effective, and their learning capacity decreases in online education. Sometimes the inability to access the internet or the internet connection problems during the lesson is another reason for dissatisfaction. Other students making noise decreases student motivation as well (Sercemeli \& Kurnaz, 2020).

\section{Methodology}

The purpose of this research is to investigate the reactions of students to this situation during the transition to online education with the interruption of education during the pandemic period. The research conducted on the students of the International Tishk University in Erbil, in the Iraqi Kurdistan region, was designed to reveal their views on online education. The questionnaire, which is shaped according to the Likert scale, made on 150 students in total, was designed to get students' opinions on the subject. The students were specifically asked about online Zoom lessons and Mercury System on which the videos were uploaded.

\section{Findings}

The first thing we inquired in this study the distribution of the students to the grades and gender. The results are shown below: 
Table 1: Graders distribution

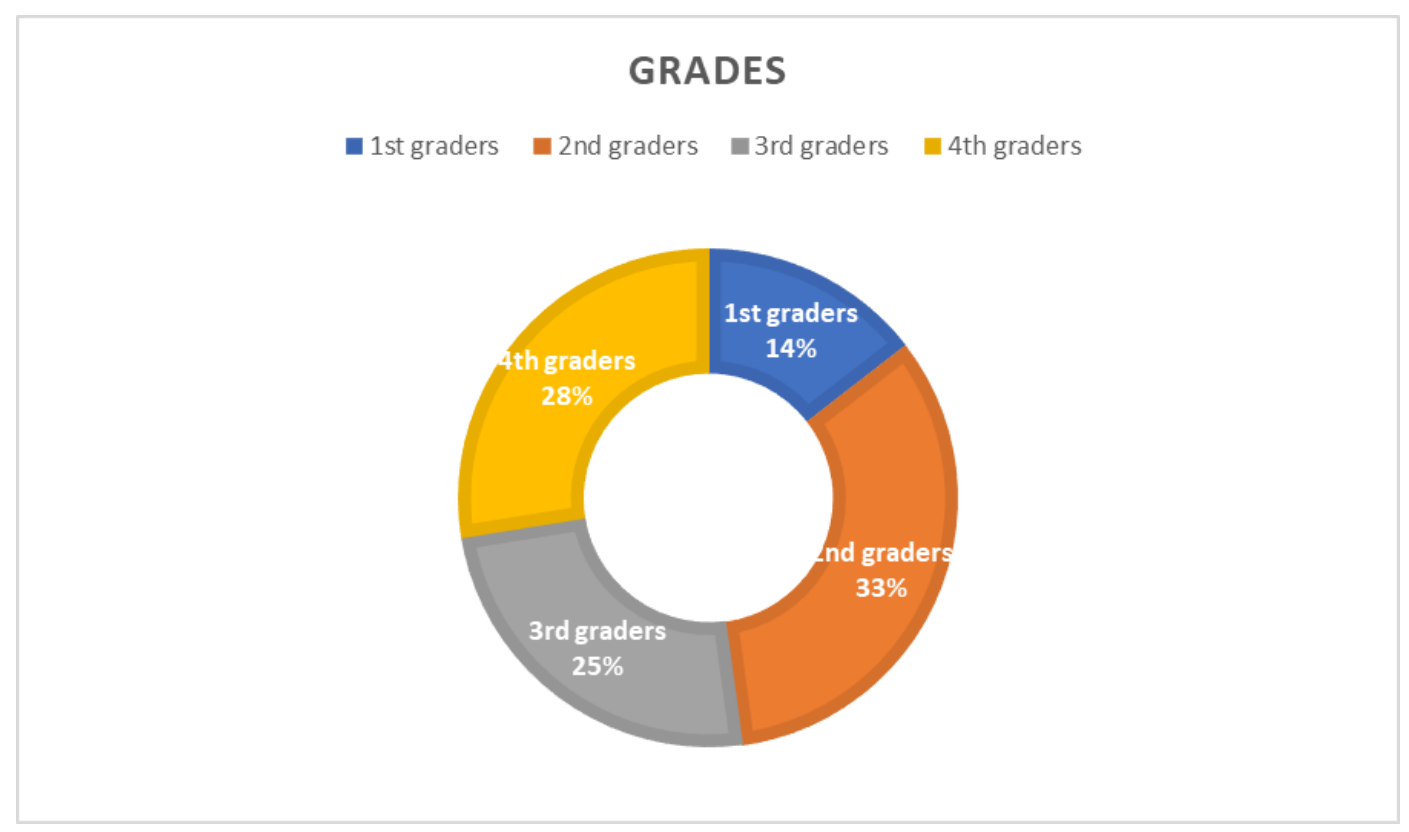

There is balanced distribution of the students to different grade levels. The reason why the first graders were less than the others proportionally is that they have just enrolled the university and they were dealing with such issues mostly.

Table 2: Gender distribution

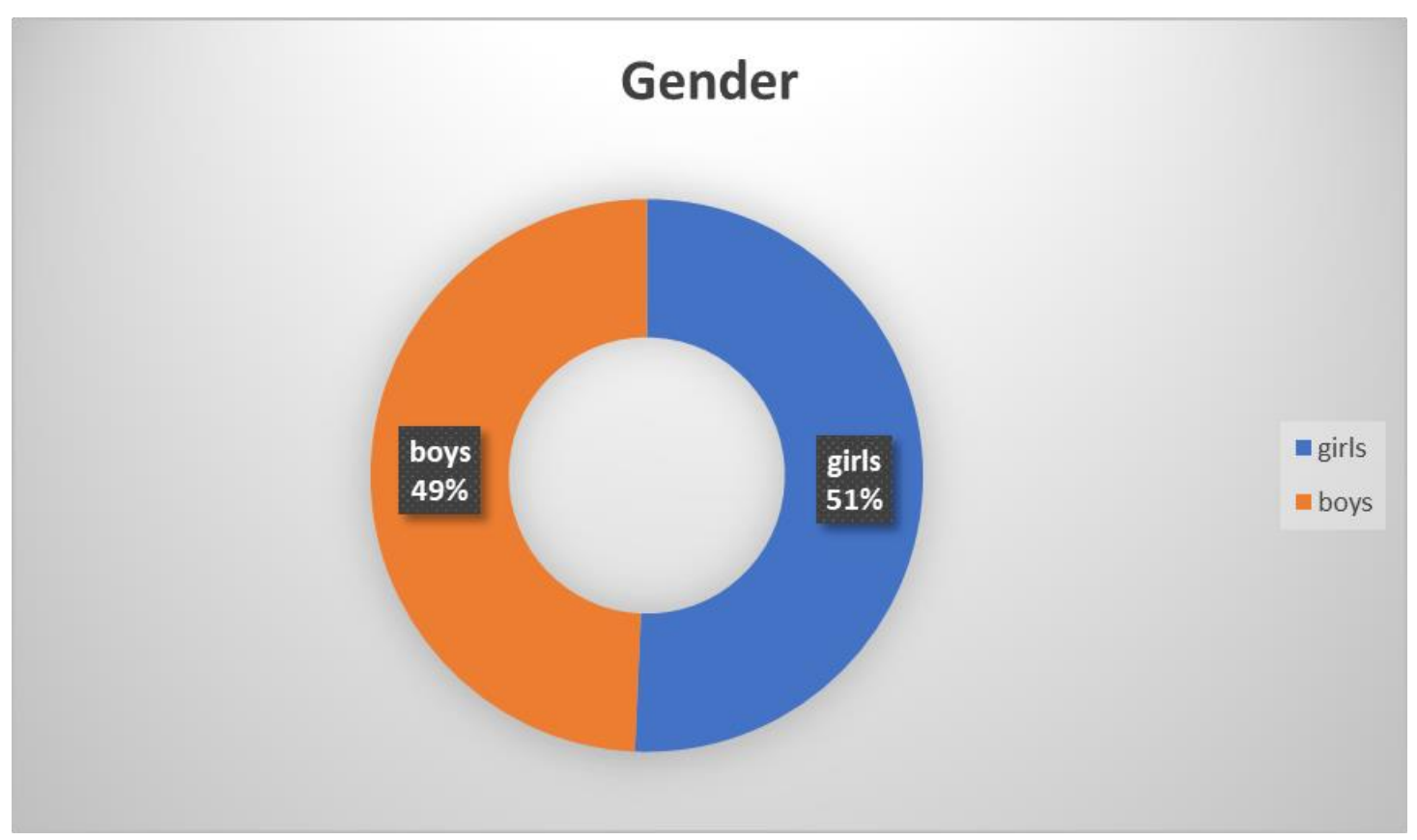


There is balanced distribution between girls and boys.

Our next question was about students' experiences with the Zoom program. Since students' online courses are conducted through this program, students were asked about their approach to this program.

Table 3: Students' experience with Zoom meetings

\section{EXPERIENCE WITH ZOOM}

I hate it $\square$ ldon't like it neutral $\square$ like it $\quad$ l love it

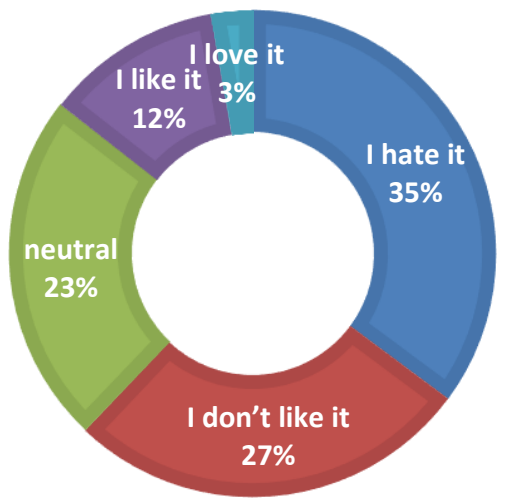

$62 \%$ of the students expressed negative opinions towards this program, while $23 \%$ remained neutral. Only $15 \%$ of the students stated positive opinions about the program. In fact, the first time they encounter the program and the first experience of online education and seeing that it is not as effective as school education are important reasons for the negative attitudes. In addition, the students of the Faculty of Dentistry we surveyed are students with high intrinsic motivation as they are the students with the highest scores in the university. Therefore, the inefficiency of these students in learning through the Zoom program according to their learning situations in the previous years has made them think this way. There are many difficulties with using this program for the first time. As students and teachers could not learn the intricacies of the program at first, they also faced many problems. After all these come together, this result is expected to appear in our survey.

The questions we asked students about the Mercury system where the lecture videos were uploaded were asked in parallel with the previous question. 
Table 4: Students' experience with Mercury System

\section{EXPERIENCE WITH MERKURY SYSTEM TO FOLLOW LECTURES.}

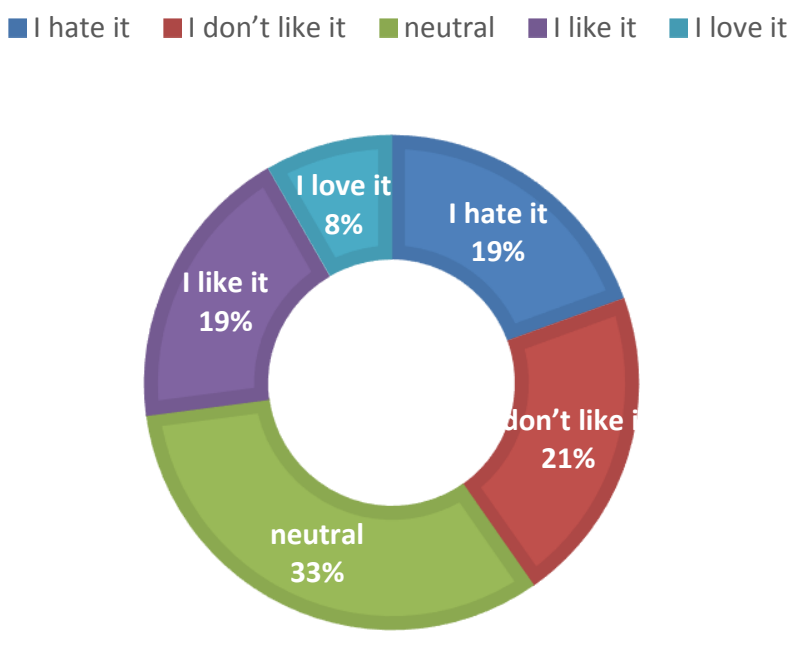

This time, we can say that the data is more positive than the above question. While $40 \%$ of the students stated negative opinions about the Mercury system, 33\% did not give any opinions. Additionally, the rate of those who expressed positive opinions increased to $27 \%$. The positive opinion, which was only 15 percent in the previous question, has increased here. Likewise, there is a decrease in negative opinions. As stated in the literature review above, it is seen that students approach video lessons more positively. Because these lessons are an important time saver for them. In addition, it is a positive situation for students to repeat this whenever they want. There may be a reason behind the high rise of negative opinions, such as students' desire for face-to-face training more.

The next question can provide important data on determining students' tendencies. The students were asked the question of whether it is more appropriate to do live lessons with their lecturers or video lessons. 
Table 5: Comparison of Online lessons with offline video lessons

\section{LIKE TO LIVE LECTURES WITH MY LECTURER INSTEAD OF OFLINE LECTURES}

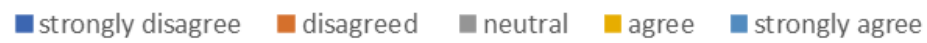

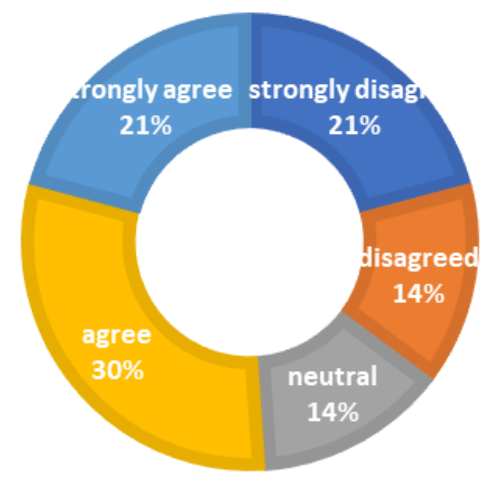

$51 \%$ of the students found it more appropriate to have live lessons with their teachers. Besides, a portion of 35\% stated negative opinion on this issue and preferred offline video lessons to the teacher's lecture. $14 \%$ did not express any opinion. As can be seen here, different opinions of the students have emerged. For some, video lessons are preferred because they can be both repeated and watched whenever they want. Others prefer live lessons more. Here, too, there were no results that would show significant differences and student ideas were distributed relatively proportionally.

The best reflection of how effectively students understand their online lessons will be on the grades they receive. That is why we asked the students whether their grades from exams during online classes met their expectations. 
Table 6: Do you think that marks you have obtained were what you have expected?

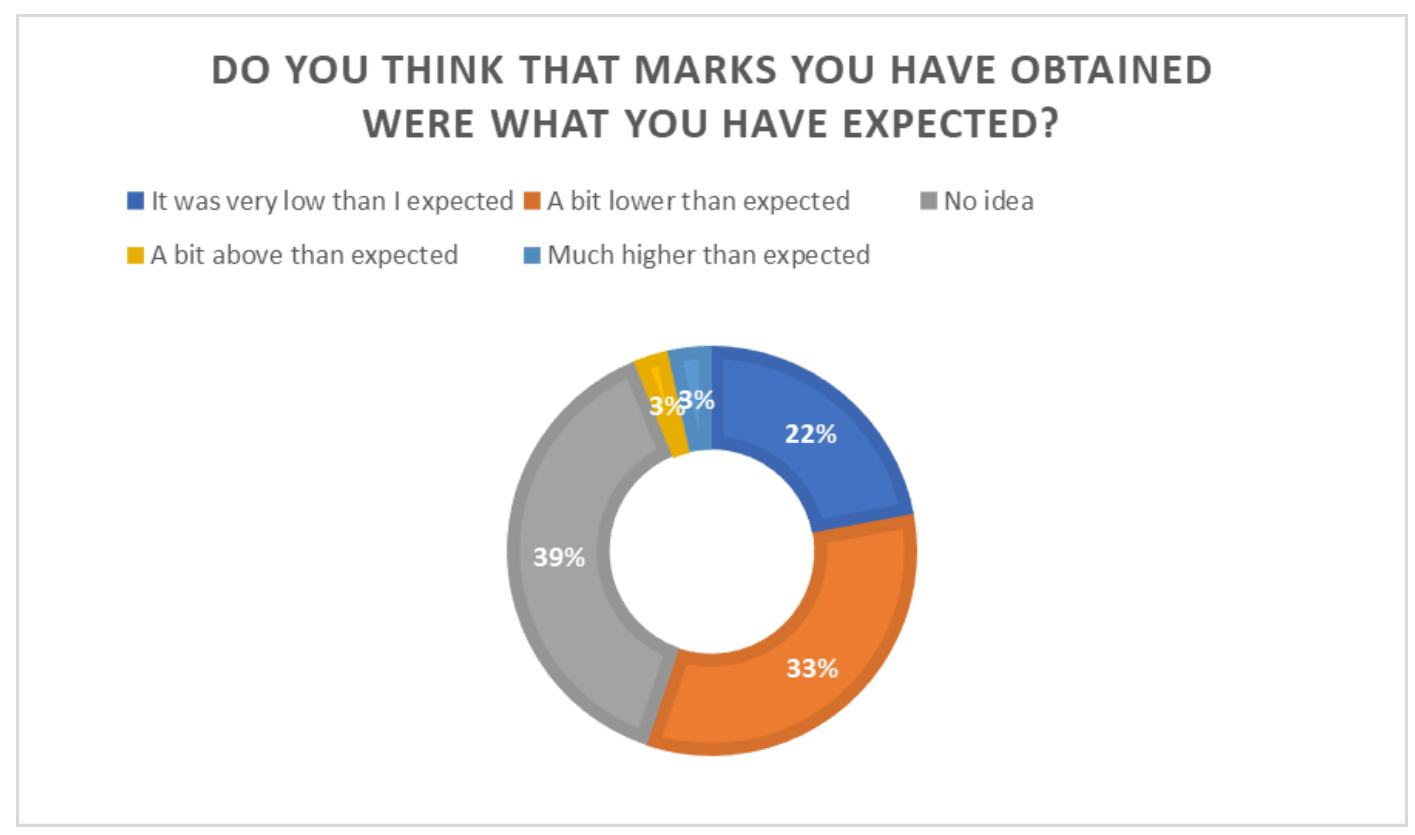

$55 \%$ of the students stated that they got grades below their expectations. 39\% did not express any opinion. The rate of students who stated that their grades were higher than they expected during this period is only 6 percent. As can be seen, this process affected the achievements and expectations of the students and caused a decrease in their success from their perspective.

What could be the reason for the decrease in students' grades is a point that needs to be investigated. In this case, the students were asked what kind of idea it was to give homework instead of an online exam or quiz. If students do not get the results, they expect from the online education they receive, it may push them to avoid exams. At this point, homework may become more attractive to them. The next question was asked at the point of researching and presenting this issue. 
Table 7: I like to have homework more than quiz or online exam.

\section{LIKE TO HAVE HOMEWORK MORE THAN QUIZ OR ONLINE EXAM NEXT SEMESTER}

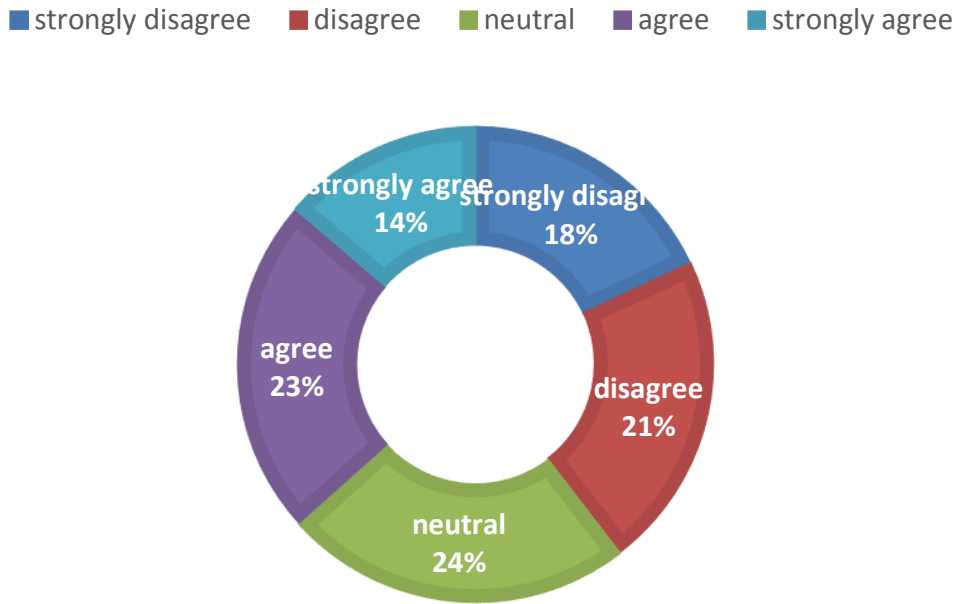

Here, a balanced distribution is observed. While the rate of those who want an online exam or quiz is $39 \%$, the rate of those who want homework is $37 \%$. The rate of those who remain undecided here is 24 percent. This balanced distribution does not provide us with meaningful data about which students want more. Half of those who expressed their opinions were positive and half were negative.

In the next question, it was investigated how the students perceive the grades they get. In other words, we investigated if they only want to get good marks, or they really want to learn the topics presented. 
Table 8: I do not like project for me only a good mark is enough

\section{DON'T LIKE PROJECTS FOR ME ONLY A GOOD MARKS IS ENOUGH.}

¿trongly desagree $\square$ Disagree $\quad$ Neutral $\quad$ Agree $\quad$ Strongly agree

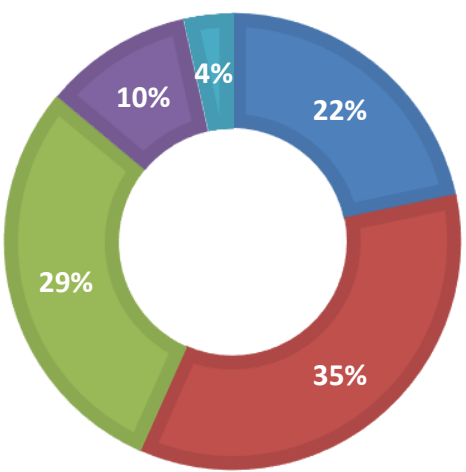

$57 \%$ of the students stated that they disagree with the idea expressed here, so there are other things for students that are more important than getting good marks. A significant portion of the students showed that they are not just behind the good mark. On the other hand, 29\% did not express any opinion. At this point, it is not clear in the question what they think of the grades, because these students may not like the projects given. On the other hand, only 14 percent of the students stated that the good mark they will get is important for them. The fact that dental faculty students are given this questionnaire may be an important factor.

We wanted to inquire what they really think of their project assignments, so we asked if they want to make some projects that are worthy of publishing later. 
Table 9: I want to make a good project with my classmates that I can publish later

\section{WANT TO MAKE A GOOD PROJECT WITH MY CLASSMATES THAT I CAN PUBLISH LATER}

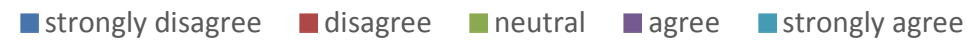

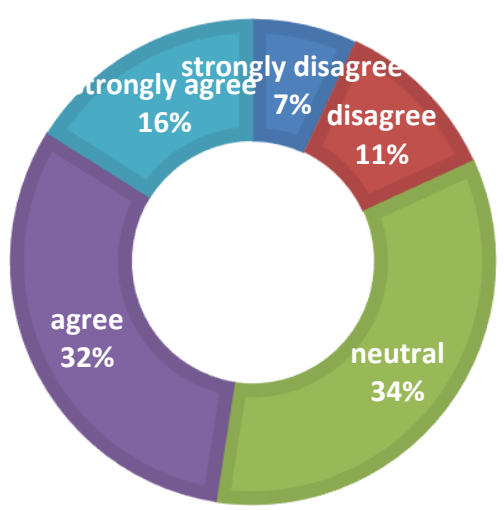

$48 \%$ expressed positive opinion about this question and they seem to be eager to prepare projects, so they are really after learning new things that will contribute to their achievement. On the other hand, 18\% percent expressed negative opinion about it, and they indicated that such hard work is not suitable for them. $34 \%$ is neutral, this may be because they are not fully aware of what a publication is because they are university students and may not know what a publication is.

The next question was asked to measure their self-confidence after they took online education which is quite different from face-to-face one. 


\section{I don't want to have a campus exam for makeup, give us only home assignments.}

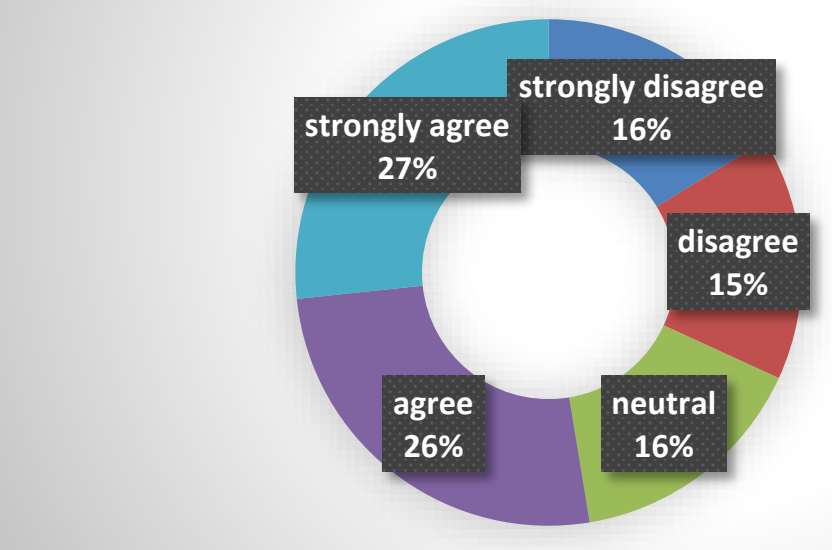

strongly disagree

disagree

neutral

agree

strongly agree

Seemingly, 53\% of them agree with the statement implying that they may not be confident enough to take a real exam. 31\% disagreed and they showed that they somehow depend on themselves about these exams, but still the percentage can be counted as quite low.

\section{Conclusion}

The coronavirus process has changed the methods people are used to in education as well as changing many habits. The adaptation process to this has been troublesome in many places and negative opinions have been expressed by students and teachers. This process, which deeply affected the education sector like all other sectors, brought about a search for solutions right after it started. The most effective solution for education has been to provide online education to students. However, this has also revealed many positive and negative aspects. In our study, the reaction of the students to this process was tried to be measured and the results obtained were similar to other studies to a certain extent. First, the change caused by the process and the transition to online education were mostly viewed negatively by students. Socialization and face-to-face education, the exact mission of the school, disappeared in this process and the students were confused about this. Students also mostly agree that online education is not as effective as face-to-face education.

Zoom lessons, which are indispensable for online education, were mostly received negatively among students, because they encountered many problems during their first experience. However, looking at the ideas about Mercury system, it is seen that they are more positive than the Zoom program, because here students can watch video lectures in accordance with their free time. A significant number of students prefer to have lessons with their teachers over offline video lessons. However, there are also students who think differently because each of the alternatives has some advantages. 
One of the important issues that students emphasize here is that they could not get the grades they expected with online education. Therefore, we can conclude that online education lowers the grades of students. It was observed that the students were divided into two when asked about their homework or online exam. Students may have different reasons for these preferences. When asked whether the students' good grades were more important than anything else, the purpose of the question was to determine what they gave more importance to. These students studying at the Faculty of Dentistry mostly agree that taking project homework and learning the lesson are more important for them. In general, we can say that this process adversely affected education as well as all other sectors.

\section{References}

Adnan, M., \& Anwar, K. (2020). Online learning amid the COVID-19 pandemic: Students' perspectives. Online Submission, 2(1), 45-51.

Basilaia, G., \& Kvavadze, D. (2020). Transition to online education in schools during a SARS-CoV-2 coronavirus (COVID-19) pandemic in Georgia. Pedagogical Research, 5(4), 1-9

Chen, T., Peng, L., Yin, X., Rong, J., Yang, J., \& Cong, G. (2020, September). Analysis of user satisfaction with online education platforms in China during the COVID-19 pandemic. In Healthcare (Vol. 8, No. 3, p. 200). Multidisciplinary Digital Publishing Institute

Di Pietro, G., Biagi, F., Costa, P., Karpinski, Z., \& Mazza, J. (2020). The likely impact of COVID-19 on education: Reflections based on the existing literature and recent international datasets. European Commission JRC Technical Report

Fontanesi, L., Marchetti, D., Mazza, C., Di Giandomenico, S., Roma, P., \& Verrocchio, M. C. (2020). The effect of the COVID-19 lockdown on parents: A call to adopt urgent measures. Psychological Trauma: Theory, Research, Practice, and Policy, 12(S1), S79-S81. http://dx.doi.org/10.1037/tra0000672

Genç, M. F., \& Gümrükçüoğlu, S. (2020). The views of theology faculty students on distance education in the coronavirus (Covid-19) Process. Electronic Turkish Studies, 15(4), 403-422

Jena, P. K. (2020). Impact of pandemic COVID-19 on education in India. International Journal of Current Research (IJCR), 12.

Khalili, H. (2020). Online interprofessional education during and post the COVID-19 pandemic: a commentary. Journal of Interprofessional Care, 34(5), 687-690

Mishra, L., Gupta, T., \& Shree, A. (2020). Online teaching-learning in higher education during lockdown period of COVID-19 pandemic. International Journal of Educational Research Open, 1, 100012.

Newman, F., \& Holzman, L. (2013). Lev Vygotsky (classic edition): Revolutionary scientist. Psychology Press.

Riccardo, F., Ajelli, M., Xanthi, A., Bella, A., Del Manso, M., Bellino, S., ... \& Rota, M. C. (2020). Epidemiological characteristics of COVID-19 cases in Italy and estimates of the reproductive numbers one month into the epidemic. medR $\chi$ iv Retrieved from http://medrxiv. org/content/early/2020/04/11/2020.04, 8.

Serçemeli, M., \& Kurnaz, E. (2020). COVID-19 Pandemi döneminde öğrencilerin uzaktan eğitim ve uzaktan muhasebe eğitimine yönelik bakiş açilari üzerine bir araştirma. Uluslararası Sosyal Bilimler Akademik Araştırmalar Dergisi, 4(1), 40-53

Toquero, C. M. (2020). Challenges and Opportunities for Higher Education amid the COVID-19 Pandemic: The Philippine Context. Pedagogical Research, 5(4) 